\title{
Growing clinical evidence for the interaction of the p53 genotype and response to induction chemotherapy in advanced non-small cell lung cancer
}

Daniela Kandioler, MD, ${ }^{\mathrm{a}, \mathrm{b}}$ Georgios Stamatis, MD, ${ }^{\mathrm{c}}$ Wilfried Eberhardt, MD, ${ }^{\mathrm{d}}$ Sonja Kappel, PhD, ${ }^{\mathrm{b}}$ Sabine Zöchbauer-Müller, MD, ${ }^{\mathrm{e}}$ Irene Kührer, MD, ${ }^{\mathrm{e}}$ Martina Mittlböck, PhD, ${ }^{f}$ Ronald Zwrtek, MD, ${ }^{g}$ Clemens Aigner, MD, ${ }^{\mathrm{h}}$ Christoph Bichler, JD, ${ }^{\mathrm{b}}$ Victoria Tichy, JD, ${ }^{\mathrm{b}}$ Marcus Hudec, PhD, ${ }^{\mathrm{i}}$ Thomas Bachleitner, MD, ${ }^{\text {a }}$ Adelheid End, MD, ${ }^{\mathrm{h}}$ Michael Rolf Müller, MD, ${ }^{h}$ Erich Roth, PhD, ${ }^{b}$ and Walter Klepetko, MD ${ }^{h}$

Earn CME credits at http:// cme.ctsnetjournals.org

From the Divisions of Surgery ${ }^{\mathrm{a}}$ and Surgical Research, ${ }^{\text {b }}$ Medical University of Vienna, Austria; Division of Thoracic Surgery, ${ }^{c}$ Ruhrland Klinik, Essen-Heidhausen, Germany; Division of Internal Medicine, ${ }^{\mathrm{d}}$ University of Essen, Germany; Division of Internal Medicine ${ }^{\mathrm{e}}$ and Section of Clinical Biometrics, ${ }^{\mathrm{f}}$ Medical University of Vienna, Austria; Division of Surgery, ${ }^{\mathrm{g}}$ Landesklinikum St Pölten, Austria; Division of Thoracic Surgery, ${ }^{\mathrm{h}}$ Medical University of Vienna, Austria; and Department of Scientific Computing, ${ }^{\mathrm{i}}$ University of Vienna, Austria.

Presented in part at the Forty-first Annual Meeting of the American Society of Clinical Oncology, Orlando, Florida, May 13-15, 2005.

Supported by national grant: Medizinisch wissenschaftlicher Fonds des Bürgermeisters der Bundeshauptstadt Wien, number 2495.

Received for publication May 2, 2007; revisions received Sept 26, 2007; accepted for publication Oct 22, 2007.

Address for reprints: Daniela Kandioler, MD, MBA, Division of Surgery, Medical University of Vienna, Waehringer Guertel 18-20, A-1090 Vienna, Austria (E-mail: Daniela.Kandioler@meduniwien.ac.at).

J Thorac Cardiovasc Surg 2008;135:103641

\section{$0022-5223 / \$ 34.00$}

Copyright $(0) 2008$ by The American Association for Thoracic Surgery

doi:10.1016/j.jtcvs.2007.10.072
Objective: The objective of this study is to establish clinical evidence that the p53 genotype can serve as a predictive marker for response to cisplatin-based induction therapy.

Methods: Patients with advanced non-small cell lung cancer who had received neoadjuvant chemotherapy in the context of a prospective phase II trial were analyzed for the p53 genotype of their tumors. Response to induction therapy was then correlated to the p53 genotype as assessed by complete direct DNA sequencing. Patients had received 3 cycles of cisplatin and etoposide, and 1 cycle of simultaneous radiochemotherapy. All 3 treatment components mediate their cytotoxic effect through induction of apoptosis, which is suggested to require an intact p53 gene. In addition, the results from a previously published hypothesis-finding study are updated to demonstrate the consistency of clinical results and summarize currently available clinical evidence.

Results: In the phase II trial, 35 patients underwent resection after induction chemotherapy, allowing a pathohistologic response assessment. The presence of a mutant p53 genotype was highly indicative of resistance to induction chemotherapy $(P<$ .002). The sensitivity of a mutant p53 genotype to identify nonresponders was $94 \%$ (71.3-99.9 confidence interval). A normal p53 gene was significantly associated with radical resection $(P<.004)$ and survival advantage $(P=.02)$.

Conclusion: This is the second clinical evaluation demonstrating a significant relation between p53 genotype and response to induction therapy in non-small cell lung cancer. We conclude that the p53 genotype should be evaluated as a predictive marker for response to induction therapy in prospective randomized protocols.

I nduction chemotherapy as treatment strategy for advanced stage non-small cell lung cancer (NSCLC) remains controversial. Despite the advantages of neoadjuvant chemotherapy (reduction of tumor burden, activity against micrometastases, patient compliance, response assessment), it is not yet widely accepted as standard treatment in advanced NSCLC. ${ }^{1}$ Multiple randomized phase III trials have shown that the use of inductive cisplatin-based chemotherapy or chemoradiation before surgery can improve survivals up to $30 \%$ at 3 years..$^{2-7}$ In an update of a systematic review, a $12 \%$ relative survival benefit equivalent to an absolute improvement in survival of $5 \%$ at 5 years was suggested. ${ }^{8}$ However, the beneficial effect of neoadjuvant chemotherapy seems to be restricted to responders only. In a recently published large randomized trial (MRC LI22/NVALT"/EORTC 08012), neoadjuvant chemotherapy resulted in a good response rate in $49 \%$ of patients. ${ }^{8}$ However the beneficial effect of neoadjuvant chemotherapy appears to be restricted to responders only. This implies that approximately $50 \%$ of patients with NSCLC currently do not benefit from standard neoadjuvant therapy. The efficacy of chemotherapy needs to be improved, and the identification of predictive markers is a promising strategy. Tumor-specific 


\section{Abbreviations and Acronyms \\ IHC = immunohistochemistry \\ NSCLC $=$ non-small cell lung cancer}

genetic alterations affecting possible pathways for chemotherapy resistance may serve as candidates to individualize and improve treatment.

The p53 gene is a well-known candidate gene for predicting response to chemotherapy. It is generally accepted that the cytotoxicity of drugs interacting with DNA is not mediated through DNA damage itself but through induction of apoptosis. DNA damage is the strongest trigger for the activation of the p53 gene, which crucially controls the apoptotic pathway. ${ }^{9-11}$ Drugs such as cisplatin and ifosfamide, etoposide, doxorubicin, cyclophosphamide, and gemcitabine, as well as radiation treatment, damage the DNA and consequently activate p53. Inactivation of the p53 gene by mutation may affect response to certain chemotherapies. ${ }^{12,13}$ Because the p53 gene seems to be the most frequent mutated gene associated with cancer, this hypothesis was addressed in various studies. ${ }^{14-16}$ In an attempt to avoid DNA sequencing, p53 was analyzed by immunohistochemistry (IHC) or screening techniques in the majority of these studies. The sensitivity of these methods to detect p53 mutations varies; consequently, inconsistent findings have been published. In the meantime, DNA sequencing is accepted as the gold standard for p53 testing. ${ }^{17}$ In vitro studies consistently show that the p53 genotype plays an important role for response to treatment. ${ }^{14,18}$ However, clinical results are still rare.

In 1999 we published a small hypothesis-finding study showing for the first time a strong relationship between the presence of a normal p53 gene and response to cisplatin/ifosfamide-based induction chemotherapy in 25 patients with NSCLC. ${ }^{16}$ For that study, we retrospectively recruited the patients at the University of Vienna; therefore, the study generated level-of-evidence $3 \mathrm{~b}$ data (retrospective cohort study).*

The aim of the current study was to advance the clinical evidence level and provide level-of-evidence $2 b$ data by analyzing a study cohort that had been recruited prospectively. Therefore, patients with advanced NSCLC who had received neoadjuvant chemotherapy in the context of a prospective phase II trial at the University of Essen, Germany, were analyzed. ${ }^{19}$ The induction treatment consisted of 3 cycles of cisplatin and etoposide and 1 cycle of simultaneous radiochemotherapy. Because the cytotoxic effect of all 3 treatment components is based on their induction of DNA damage, this cohort seemed suitable for testing the hypothesis.

\footnotetext{
* Oxford Centre of Evidence-based Medicine levels of Evidence, May 2001: www.cebm.net
}

This study adds clinical evidence to the suggested interaction between the p53 genotype and the chemotherapy response. In addition, our previously published hypothesisfinding study is updated to demonstrate the consistency of clinical results and summarize currently available clinical data because the number of patients is still small.

\section{Materials and Methods}

In 1999, Stamatis and coworkers ${ }^{19}$ reported the results of a prospective phase II trial that included 56 patients with stage IIIA and IIIB NSCLC. In this trial, patients received 3 cycles of cisplatin $(60 \mathrm{mg} /$ $\mathrm{m}^{2}$ days $\left.1+7\right)$ and etoposide $\left(150 \mathrm{mg} / \mathrm{m}^{2}\right.$ days $\left.3-5\right)$, followed by 1 cycle of simultaneous radiochemotherapy (cisplatin $50 \mathrm{mg} / \mathrm{m}^{2}$ days $2+9$, etoposide $100 \mathrm{mg} / \mathrm{m}^{2}$ days $4-6$, thoracic irradiation $45 \mathrm{~Gy}$ ). After induction therapy, 35 of 56 patients were surgically resectable. For the present analysis, tumor material and response data of the 35 surgically resected patients were provided for p53 analysis.

Patient data and genetic material were handled at the p53 research laboratory at the Surgical Research Laboratories of the Medical University of Vienna under the oversight of the university's ethics committee. The laboratory is officially certified by the national ministry of health in performing molecular genetic analyses of the p53 gene and handling patient data.

Archived paraffin-embedded tumor material from the diagnostic biopsies of patients who were included in the prospective phase II trial was sent to our laboratory for p53 sequencing. The sequencing results were then correlated to the response data provided. As a control, the provided response data were compared with the data from the pathohistologic reports.

\section{Response Category}

The 4 response evaluation criteria in solid tumors (RECIST categories $)^{20}$ - complete remission, partial remission, stable disease, and progressive disease-were grouped in responders (including complete remission and partial remission) and nonresponders (including stable disease and progressive disease) for statistical evaluation.

\section{Statistical Methods}

The 2 (grouped) categories of response to induction treatment (responders, nonresponders) were correlated with the p53 genotype (mutated or normal).

The data in the various categories were described with frequencies and percentages, and corresponding associations among the data were tested with chi-square tests. In cases in which only few data were available, a Fisher exact test was calculated for $2 \times 2$ tables and an exact Pearson test was calculated for $2 \times 3$ tables. The diagnostic value of the $\mathrm{p} 53$ gene with regard to response to induction treatment was assessed with sensitivity, specificity, and corresponding 2-sided $95 \%$ confidence intervals. In cases of $100 \%$ sensitivity or specificity, corresponding 1-sided $95 \%$ confidence intervals were provided. Survival data are graphically described with Kaplan-Meier curves and tested with log-rank test and Wilcoxon tests. ${ }^{21,22}$ All $P$ values are 2 -sided.

\section{P53 Gene Sequencing}

Complete DNA sequencing was carried out to assess the p53 genotype and identify mutations in the p53 gene using complete direct DNA sequencing. Tumor DNA was prepared from sections from 
TABLE 1. Characteristics of investigated patient cohorts

\begin{tabular}{|c|c|c|c|}
\hline & Hypothesis-finding study & Actual study & \\
\hline & Cisplatin/ifosfamide & Cisplatin/etoposide/radiation & Combined evaluation \\
\hline No. of patients & 24 & 35 & 59 \\
\hline Mean age (y) & $59.3 \pm 10.7$ & $54.9 \pm 7.9$ & $56.9 \pm 9.3$ \\
\hline Median follow-up (mo) & 43.6 & 64.7 & 53.2 \\
\hline No. of p53 mutations & $8(33 \%)$ & $11(31 \%)$ & $19(32 \%)$ \\
\hline
\end{tabular}

The actual study describes the new patient cohort. The hypothesis-finding study contains updated information on our previously published data.

tumor tissues that were obtained in the course of diagnostic biopsies or surgery. The methods of DNA extraction, polymerase chain reaction amplification of the $\mathrm{p} 53$ gene, and purification of the polymerase chain reaction product have been published. ${ }^{16}$

\section{Sequencing with the ABI Prism 310}

Direct sequencing was done using the ABI Prism BigDye Terminator Cycle Sequencing Ready Reaction Kit (PE Applied Biosystems, Foster City, Calif). Amplification was performed in a total volume of $10 \mu \mathrm{L}$ for 25 cycles using $2 \mu \mathrm{L}$ of purified polymerase chain reaction product, 2 pmol of primer (sense or antisense), and $2 \mu \mathrm{L}$ of Terminator Ready Reaction Mix. For T1 Thermocycler (Biometra, Göttingen, Germany), the following thermal profiles were used: 10 -second denaturation at $96^{\circ} \mathrm{C}, 5$-second annealing at $50^{\circ} \mathrm{C}$, and 4-minute extension at $60^{\circ} \mathrm{C}$. Sequence reaction was then purified by Centri Sep spin columns (Princeton Separations P/N CS-901, Adelphia, NJ). Sequence analysis was performed with the ABI Prism 310 Genetic Analyzer (PE Applied Biosystems).

\section{Results}

\section{Patient Characteristics}

Patient characteristics are shown in Table 1. Patients of the actual prospective study differed from patients of the hypothesis-finding study in that the proportion of squamous cell carcinoma was higher ( $74 \%$ vs $50 \%)$. No significant association between histologic type and p53 mutation could be found (Table 2). The proportion of patients with more advanced disease (stage IIIB) was higher in the actual study cohort compared with the hypothesis-finding study cohort. The summarized analysis of the 59 patients reveals that mutations in the p53 gene are more frequently present in the advanced stage (IIIB) (Table 2), which is consistent with the literature (International Agency for Research on Cancer database).

\section{Predicting the Response to Induction Treatment}

We identified a strong correlation between patients with a normal p53 gene and an effective response to cisplatinbased induction treatment in both studies (Table 3). A mutant p53 genotype was highly indicative of resistance to the induction treatment regimens used in the 2 studies (cisplatin/ ifosfamide in the hypothesis-finding study and cisplatin/ etoposide/radiation in the actual study).

The sensitivity of predicting response to treatment by $\mathrm{p} 53$ status was as high as $94 \%$ in the actual study compared with $100 \%$ in the hypothesis-finding study and $97 \%$ when both studies were considered together. A normal p53 gene was significantly associated with radical resection in both studies (Table 3).

\section{Overall Patient Survival}

Patients with a normal p53 gene had a significant survival advantage over patients with mutated p53 (Figure 1).

\section{Characterization of p53 Mutation}

Table 4 characterizes the p53 mutations found in the actual study: Three mutations (numbers 864,874 , and 875 ) were found to result in the formation of a STOP codon (representing

TABLE 2. Association of clinicopathologic variables and p53 genotype

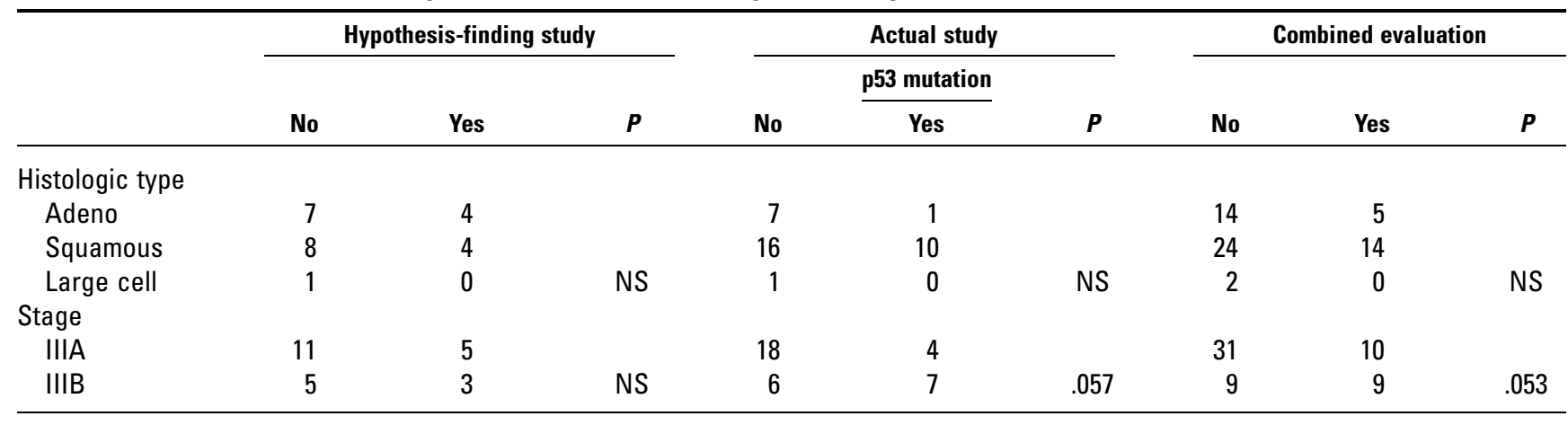

NS, Not significant. 
TABLE 3. P53 genotype in relation to response to neoadjuvant therapy and radical resection

\begin{tabular}{|c|c|c|c|c|c|c|c|c|c|c|c|c|}
\hline & \multicolumn{4}{|c|}{ Hypothesis-finding study } & \multicolumn{4}{|c|}{ Actual study } & \multicolumn{4}{|c|}{ Combined evaluation } \\
\hline & p53 normal & & p53 mutant & $P$ value & p53 normal & & p53 mutant & $P$ value & p53 normal & & p53 mutant & $P$ value \\
\hline \multicolumn{13}{|c|}{ Pathologic response } \\
\hline Responder & $16(100 \%)$ & & 0 & & $16(94 \%)$ & & $1(6 \%)$ & & $32(97 \%)$ & & $1(3 \%)$ & \\
\hline \multirow[t]{2}{*}{ Nonresponder } & 0 & & $8(100 \%)$ & $<.001$ & $8(44 \%)$ & & $10(56 \%)$ & .002 & $8(31 \%)$ & & $18(69 \%)$ & $<.001$ \\
\hline & 16 & & 8 & & 24 & & 11 & & 40 & & 19 & \\
\hline Sensitivity & $100 \%(16 / 16)$ & $\mathrm{Cl}:$ & $82.9-100$ & & $94 \%(16 / 17)$ & $\mathrm{Cl}:$ & $71.3-99.9$ & & $97 \%(32 / 33)$ & Cl: & 84.3-99.9 & \\
\hline Specificity & $100 \%(8 / 8)$ & $\mathrm{Cl}:$ & $68.7-100$ & & $56 \%(10 / 18)$ & $\mathrm{Cl}:$ & $30.7-78.5$ & & $69 \%(18 / 26)$ & $\mathrm{Cl}:$ & $48.2-85.7$ & \\
\hline \multicolumn{13}{|l|}{ Radical resection } \\
\hline Yes & $16(100 \%)$ & & $4(50 \%)$ & & $17(90 \%)$ & & $2(10 \%)$ & & $33(85 \%)$ & & $6(15 \%)$ & \\
\hline \multirow[t]{2}{*}{ No } & 0 & & $4(50 \%)$ & .007 & $7(44 \%)$ & & $9(56 \%)$ & .004 & $7(35 \%)$ & & $13(65 \%)$ & $<.001$ \\
\hline & 16 & & 8 & & 24 & & 11 & & 40 & & 19 & \\
\hline
\end{tabular}

$\mathrm{Cl}$, Confidence interval.

2 frameshifts and 1 nonsense mutation), which is deleterious for the biologic activity of the p53 gene.

One mutant was found to be a silent mutation (number 842), which does not alter the amino acid sequence of the encoded protein. Therefore, the affected patient was considered as "p53 normal" for our analyses.

\section{Discussion}

The present publication clinically demonstrates a significant relation between the $\mathrm{p} 53$ genotype and the response to induction therapy. In this study, the "p53 genotype" is analyzed by complete DNA sequencing and shows consistent predictive power compared with our previously published hypothesisfinding study. Both studies suggest that the p53 genotype could serve as a predictive marker for a patient's response to cisplatin-based induction therapy in advanced NSCLC.

\section{P53 Analysis Method}

The impact of the p53 gene on the response to chemotherapy has been addressed in vitro and in some clinical trials. However, because of conflicting results obtained in previous studies, p53 has not been considered a useful predictive marker in NSCLC. ${ }^{23}$

Several factors account for the conflicting results. First, a wide range of techniques have been used for p53 analysis to avoid complete direct sequencing of the whole gene. Different electrophoresis-based screening techniques have been applied in selecting patients to be sequenced. Additional sequencing, if applied, was often restricted to parts of the gene (exons 5-8). Therefore, the mutation frequency is likely to be underreported in such studies.

The use of p53 IHC is based on the observation that missense mutations alter the protein structure, inhibiting rapid degradation of the protein. Therefore, accumulation of p53 protein was suggested to indicate the presence of p53 gene mutations. Different antibodies and cutoffs were used to determine a tumor as p53-accumulation positive. Apart from this lack of standardization, the sensitivity and specificity of IHC are affected by false-positive and false-negative IHC results: Accumulation of the p53 protein can occur as a result of physiologic stabilization or overexpression resulting from genotoxic stress. Because most antibodies are not able to discriminate between wild-type and mutant p53 protein, this will result in false-positive IHC. Complete absence of $\mathrm{p} 53$ protein can be caused by deleterious gene mutations. The latter prevent the transcription of the gene and result in false-negative IHC results. $^{24}$

Because of the inherent bias concerning the analytic techniques that have been used, the results of existing studies assessing the predictive value of p53 are of limited value. In our recent review of the literature on the predictive value of $\mathrm{p} 53$ in the treatment of breast cancer, response to treatment seems to be consistent and linked to the p53 sequencing results but not to IHC. ${ }^{17}$

Complete direct sequencing of the entire p53 gene (exons 2-11) is currently the most reliable, standardized, and sensitive method to evaluate p53 gene mutations.

\section{Chemotherapy Resistance in NSCLC}

d'Amato and colleagues ${ }^{25}$ recently published preclinical data on the resistance of NSCLC tumor cell cultures to several chemotherapy agents. They found that tumor cells were frequently resistant to at least 1 agent in chemotherapy doublet regimens and expressed a possible association between drug resistance and p53 overexpression. They observed that many tumors exhibit simultaneous resistance to platinum agents and gemcitabine. Because both drugs act via induction of DNA damage, these findings support the hypothesis that functional p53 is required to induce apoptosis as a result of DNA damage. The reported resistance rates of $60 \%$ to $80 \%$ can be explained by the high p53 mutation rates frequently observed in cell cultures. $^{26}$

\section{Conclusions}

We provide clinical evidence that a normal p53 genotype can identify patients with NSCLC who will benefit from standard 

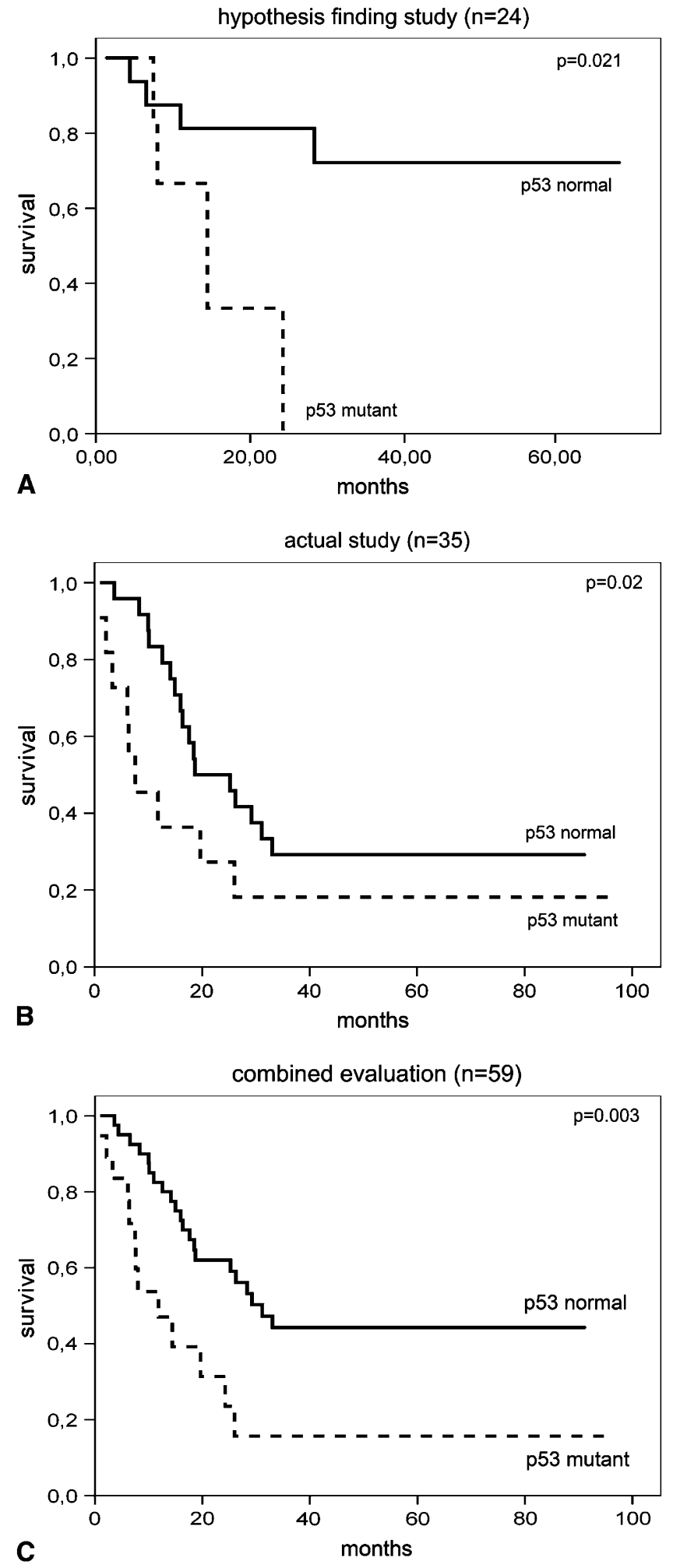

Figure 1. Survival benefit after neoadjuvant therapy is related to a normal p53 genotype in both clinical evaluations, A, Four-year update of the retrospective, hypothesis finding study; B, Prespective, actual study; C, Combined calculation of 59 patients.
TABLE 4. Characterization of p53 mutations in the actual study cohort

\begin{tabular}{llc}
\hline Patient No. & \multicolumn{1}{c}{ TP53 mutant } & Mutant codon \\
\hline 835 & c.578A $>$ T (p.His193Leu) & CTT \\
836 & c.743G $>$ T (p.Arg248Leu) & CTG \\
842 & c.489C $>$ T (p.Tyr163Tyr) & TAT silent* \\
850 & $c .746 G>T$ (p.Arg249Met) & ATG \\
857 & $c .524 G>$ A (pArg175His) & CAC \\
859 & $c .747 G>T$ (p.Arg249Ser) & AGT \\
860 & $c .461 G>T$ (p.Gly154Val) & GTC \\
864 & $c .521537$ del (p.Arg174_Arg 179fsX6) & Frameshift \\
872 & $c .746 G>T$ (p.Arg249Met) & ATG \\
874 & $c .731$ del G (pGly244 AlafsX3) & Frameshift \\
875 & $c .511 G>T$ (p.Glu171X) & TAG \\
876 & $c .747 G>T$ (p.Arg249Ser) & AGT
\end{tabular}

*This mutation does not alter the amino acid residue and therefore was calculated as p53 normal. However, this alteration can affect mRNA splicing, stability, and so forth, and clinically the patient did not respond to chemotherapy.

cisplatin-based induction treatment. We demonstrate that the presence of a normal p53 gene results in response to induction therapy. In the group of responders, we observed a high rate of radical resections and prolonged overall survival.

On the basis of the consistent results of our clinical analyses, we conclude that the p53 genotype should be evaluated as a predictive marker in randomized, neoadjuvant protocols for NSCLC. Upcoming protocols should consider the technical aspects of p53 analysis and allow correct response assessment.

\section{References}

1. Wang G, Reed E, Li QQ. Molecular basis of cellular response to cisplatin chemotherapy in non-small cell lung cancer (Review). Oncol Rep. 2004; 12:955-65.

2. Roth JA, Fossella F, Komaki R, Ryan MB, Putnam JB Jr, Lee JS, et al. A randomized trial comparing perioperative chemotherapy and surgery with surgery alone in resectable stage IIIA non-small-cell lung cancer. J Natl Cancer Inst. 1994;86:673-80.

3. Roth JA, Atkinson EN, Fossella F, Komaki R, Bernadette Ryan M, Putnam JB Jr, et al. Long-term follow-up of patients enrolled in a randomized trial comparing perioperative chemotherapy and surgery with surgery alone in resectable stage IIIA non-small-cell lung cancer. Lung Cancer. 1998;21:1-6.

4. Rosell R, Gomez-Codina J, Camps C, Maestre J, Padille J, Canto A, et al. A randomized trial comparing preoperative chemotherapy plus surgery with surgery alone in patients with non-small-cell lung cancer. N Engl J Med. 1994;330:153-8.

5. Rosell R, Gomez-Codina J, Camps C, Javier Sanchez J, Maestre J, Padilla J, et al. Preresectional chemotherapy in stage IIIA non-smallcell lung cancer: a 7-year assessment of a randomized controlled trial. Lung Cancer. 1999;26:7-14.

6. Dillman RO, Herndon J, Seagren SL, Eaton WL Jr, Green MR. Improved survival in stage III non-small-cell lung cancer: seven-year follow-up of cancer and leukemia group B (CALGB) 8433 trial. J Natl Cancer Inst. 1996;88:1210-5.

7. Sause WT, Scott C, Taylor S, Johnson D, Livingston R, Komaki R, et al. Radiation Therapy Oncology Group (RTOG) 88-08 and Eastern Cooperative Oncology Group (ECOG) 4588: preliminary results of a phase III 
trial in regionally advanced, unresectable non-small-cell lung cancer. J Natl Cancer Inst. 1995;87:198-205.

8. Gilligan D, Nicolson M, Smith I, Groen H, Dalesio O, Goldstraw P, et al. Preoperative chemotherapy in patients with resectable non-small cell lung cancer: results of the MRC LU22/NVALT 2/EORTC 08012 multicentre randomised trial and update of systematic review. Lancet. 2007; 369:1929-37.

9. Pirollo KF, Bouker KB, Chang EH. Does p53 status influence tumor response to anticancer therapies? Anticancer Drugs. 2000;11:419-32.

10. Peller S. Clinical implications of p53: effect on prognosis, tumor progression and chemotherapy response. Semin Cancer Biol. 1998;8: 379-87.

11. Lowe SW, Ruley HE, Jacks T, Housman DE. p53-dependent apoptosis modulates the cytotoxicity of anticancer agents. Cell. 1993;74:957-67.

12. Bates S, Vousden KH. Mechanisms of p53-mediated apoptosis. Cell Mol Life Sci. 1999;55:28-37.

13. Lowe SW, Bodis S, McClatchey A, Remington L, Ruley HE, Fisher DE, et al. p53 status and the efficacy of cancer therapy in vivo. Science. 1994; 266:807-10.

14. Lai SL, Perng RP, Hwang J. p53 gene status modulates the chemosensitivity of non-small cell lung cancer cells. J Biomed Sci. 2000;7:64-70.

15. Bergqvist $\mathrm{M}$, Brattstrom $\mathrm{D}$, Gullbo J, Hesselius $\mathrm{P}$, Brodin $\mathrm{O}$, Wagenius G. p53 status and its in vitro relationship to radiosensitivity and chemosensitivity in lung cancer. Anticancer Res. 2003;23(2B): 1207-12.

16. Kandioler-Eckersberger D, Kappel S, Mittlbock M, Dekan G, Ludwig C, Janschek E, et al. The TP53 genotype but not immunohistochemical result is predictive of response to cisplatin-based neoadjuvant therapy in stage III non-small cell lung cancer. J Thorac Cardiovasc Surg. 1999;117:744-50.

17. Kandioler D. p53 as a prognostic and predictive indicator. In: Gasparini G, Hayes F, eds. Biomarkers in Breast Cancer Molecular Diagnostics for Predicting and Monitoring Therapeutic Effect. Totowa: Humana Press; 2005:193-209.

18. Shaik MS, Chatterjee A, Jackson T, Singh M. Enhancement of antitumor activity of docetaxel by celecoxib in lung tumors. Int J Cancer. 2006; 118:396-404.

19. Stamatis G, Eberhardt W, Stuben G, Bildat S, Dahler O, Hillejan L. Preoperative chemoradiotherapy and surgery for selected non-small cell lung cancer IIIB subgroups: long-term results. Ann Thorac Surg. 1999;68:1144-9.

20. Therasse P, Arbuck SG, Eisenhauer EA, Wanders J, Kaplan RS, Rubinstein L, et al. New guidelines to evaluate the response to treatment in solid tumors. European Organization for Research and Treatment of Cancer, National Cancer Institute of the United States, National Cancer Institute of Canada. J Natl Cancer Inst. 2000;92:205-16.

21. Mantel N. Evaluation of survival data and two new rank order statistics arising in its consideration. Cancer Chemother Rep. 1966;50:163-70.

22. Klingler A. Statistical methods in surgical research-a practical guide. Eur Surg. 2004;36:80-4.

23. Viktorsson K, De Petris L, Lewensohn R. The role of p53 in treatment responses of lung cancer. Biochem Biophys Res Commun. 2005;331: $868-80$.

24. Steels E, Paesmans M, Berghmans T, Branle F, Lemaitre F, Mascaux C, et al. Role of p53 as a prognostic factor for survival in lung cancer: a systematic review of the literature with a meta-analysis. Eur Respir J. 2001; 18:705-19.

25. d'Amato TA, Landreneau RJ, Ricketts W, Huang W, Parker R, Mechetner E, et al. Chemotherapy resistance and oncogene expression in non-small cell lung cancer. J Thorac Cardiovasc Surg. 2007;133: $352-63$.

26. vom Brocke J, Schmeiser HH, Reinbold M, Hollstein M. MEF immortalization to investigate the ins and outs of mutagenesis. Carcinogenesis. 2006;27:2141-7. 